\title{
Geleitwort des Herausgebers der Sammlung
}

In dem vorliegenden Band 5 dieser Monographien-Sammlung: P. Sмпт, ,Ionenaustauscher bei der Herstellung und Reinigung von Zuckern, Pektinen und verwandten Stoffen", legt der bekannte holländische Ingenieur und Zuckertechniker seine vielfältigen Erfahrungen dar, die er im Laufe von mehr als drei Jahrzehnten in zum großen Teil eigener Versuchsarbeit über die Anwendung von Ionenaustauschern und Adsorbern in der Zuckerindustrie gesammelt hat. Der Leser, der seiner Darstellung folgt, geht mit ihm den langen Weg der Gewinnung und Reinigung zuckerhaltiger Produkte, der, mit primitivsten Arbeitsmethoden beginnend, unter allmählicher Vervollkommnung der apparativen wie der adsorptiven Hilfsmittel in unser technisches Zeitalter führt, in welchem höchste Ansprüche an die Güte der mannigfachen Produkte mit der Forderung hoher Wirtschaftlichkeit der Herstellungsverfahren zu vereinigen sind.

Es ist imponierend, an der Hand der Ausführungen von P. SMrT zu erkennen, wie Zuckerfachleute aller Kulturländer in großer Versuchsfreudigkeit daran mitgearbeitet haben, die mannigfachsten Naturstoffe und Kunstprodukte auf ihre Reinigungs-(Klär- und Entfärbungs-)wirkung für Zuckersäfte zu erproben, bis schließlich die Austauschadsorbentien auf Kunstharzbasis auf Grund der Vielseitigkeit ihrer Wirkungen den Sieg über früher angewandte Mittel davontrugen.

Dieser historischen Vorschau läßt der Autor eine kurze, von großer Sachkenntnis getragene, Kennzeichnung der Ionenaustauscher auf Kunstharzbasis hinsichtlich Eigenschaften wie Reaktionsmöglichkeiten folgen. Wertvolle Hinweise auf die zweckmäßigsten apparativen Hilfsmittel und für ihre richtige Bedienung schließen sich an.

Der zentrale Teil des Werkes ist der Anwendung ionenaustauschender Kunstharze zur Enthärtung und Entmineralisierung von Zuckerlösungen gewidmet. Der Leser wird mit den bei der Einführung in die Zuckerpraxis aufgetretenen Anlaufschwierigkeiten bekanntgemacht und mit den mannigfachen Vorschlägen zu deren Überwindung.

Der Autor verweilt alsdann bei den zahlreichen, von verschiedenster Seite ergangenen Vorschlägen spezieller Verfahren, die - obwohl oft recht interessant zumeist heute noch der Verwirklichung harren:

Mehrfach wird z. B. das Arbeiten mit Hilfsionen empfohlen, insbesondere das Einführen von Ammoniak, um damit eine Kreislaufführung der Säfte und 
Regeneriermittel zu erreichen bzw. die Erzeugung der letzteren im eigenen Betriebe sicherzustellen, u. a. m.

Technisch durchgesetzt hat sich bekanntlich die Entionisierung der Dünnsäfte, d. h. man hat es für zweckmäßig gehalten, die bisher übliche Kalkung der Rohsäfte als Vorreinigungsstufe beizubehalten, ehe man über die Austauscher filtriert.

Den Höhepunkt des P. Surtschen Buches bildet ohne Zweifel der Bericht über seine eigene umfangreiche Versuchsarbeit, die in dem „Neuen Verfahren“ gipfelt, dem Vorschlag, mit den Ionenaustauschern unmittelbar an die Behandlung der Rohsäfte heranzugehen. Dabei kann sich der Autor im wesentlichen auf zwei Tatsachen stützen: die Beobachtung der hervorragenden Klärwirkung der Kunstharzaustauscher (zumal des Kationenaustauschers in der $\mathrm{H}^{*}$-Form) auf den so kolloidreichen Rohsaft, und ferner die hohe mechanische und chemische Stabilität der heute zur Verfügung stehenden Kationenaustauscher auf Polymerisatbasis, welche die Anwendung selbst sehr rigoroser Reinigungsmethoden zulassen.

Bezüglich des Inhaltes der nachfolgenden Kapitel können im Hinblick auf das dem Buche beigegebene ausführliche Sachverzeichnis - ein Blick genügt, um die Gründlichkeit und Vielseitigkeit der Darstellung zu erkennen, - einige wenige Hinweise ausreichen:

Die Entionisierung hat sich auch bei Lösungen anderer Zuckerarten, Monound Polysacchariden, sowie Stoffen ähnlicher Art bewährt.

Die selektive Anreicherung diverser Stoffe auf den Austauschern und sodann in bestimmten Regeneratanteilen hat dazu geführt, auch den Nebenbestandteilen von Rübe und Rohr größere Beachtung zu schenken. Mancher früher unerwünschte oder gar schädliche Bestandteil ist inzwischen zu einem wertvollen Nebenprodukt der Zuckerfabrikation geworden oder dabei, es zu werden.

Möge dieses Buch, von einem Praktiker für den Praktiker geschrieben, mit seinen an zahlreichen Stellen eingestreuten wertvollen praktischen Winken dazu dienen, Anlaufschwierigkeiten beim Einsatz von Ionenaustauschern zu überwinden und Vorurteile zu beseitigen, wenn es sich darum handelt, den Kunstharzadsorbentien neue Anwendungsgebiete zu erschließen oder neue Entwicklungsrichtungen zu erproben; möge das Werk somit dazu beitragen, den Austauschadsorbentien neue Freunde zu gewinnen.

Wolfen, im Mai 1968

R. Grießbach 